\title{
Active site elucidation and optimization in Pt co-catalysts for photocatalytic hydrogen production over titania
}

\author{
Zhi Jiang, ${ }^{*[a]}$ Mark A. Isaacs, ${ }^{[b]}$ ZhengWen Huang, ${ }^{[a]}$ Wenfeng Shangguan, ${ }^{[a]}$ Yifeng Deng, ${ }^{[c]}$ and Adam \\ F. Lee ${ }^{*[b]}$
}

Abstract: Platinum co-catalysts play a critical role in promoting the photocatalytic performance of inorganic semiconductors, yet despite intensive investigation, the active platinum species responsible remains controversial. Here the physicochemical properties of $\mathrm{Pt}$ nanoparticles introduced into anatase titania through three different synthetic protocols are investigated by porosimetry, XRD, XPS and XAS and correlated with their corresponding activity for aqueous photocatalytic hydrogen production. Conventional wet impregnation produces small but highly oxidized platinum nanoparticles due to the classical strong metal-support interaction with titania during high temperature processing. Photodeposition yields predominantly metallic but large and inhomogeneous (1.5-7.5 nm) Pt nanoparticles. In contrast, a modified in-situ polyol route affords metallic and highly dispersed $\left(<2 \mathrm{~nm}\right.$ ) nanoparticles with minimal $\mathrm{PtO}_{x}$. Photocatalytic $\mathrm{H}_{2}$ evolution is directly proportional to the surface concentration of $\mathrm{Pt}$ metal, conclusively demonstrating metallic platinum as the active cocatalyst, and offering a simple parameter to quantitatively predict the photocatalytic performance of $\mathrm{Pt} / \mathrm{TiO}_{2}$ in $\mathrm{H}_{2}$ production. The modified in-situ polyol synthesis is optimal for co-catalyst formation, delivering rate enhancements of $25-80 \%$ compared to the other syntheses.

\section{Introduction}

Light-driven water splitting for the direct production of molecular hydrogen is one of the most promising routes to solar energy conversion and storage [1]. Inorganic semiconductors are promising materials to effect this photochemical conversion, whose efficiency mainly depends on successful charge creation, separation and migration within the semiconductor ${ }^{[2]}$, as well as the kinetics of the subsequent bond breaking and making surface reactions, which are in turn strongly influenced by the presence and nature of co-catalysts on the semiconductor surface ${ }^{[3]}$. The role of the latter is often neglected, hindering the rational design of co-catalysts and their associated impact on photocatalytic performance in water splitting.

[a] Dr.Z. Jiang, Prof. Dr. W.Shangguan

Research Center for Combustion and Environment Technology

Shanghai Jiao Tong University

Shanghai, China

E-mail: zhijiang@sjtu.edu.cn

[b] Dr. M.A. Isaacs, Prof. Dr. A.F.Lee

European Bioenergy Research Institute

Aston University

Birmingham, UK

E-mail: a.f.lee@aston.ac.uk

[c] Mr. Y.Deng

Pinghe School

Shanghai, China

Supporting information for this article is given via a link at the end of the document
Transition metal nanoparticles represent the most common co-catalysts employed to promote semiconductor photocatalysts, notably Pt, however contradictory findings are reported regarding the oxidation state of $\mathrm{Pt}$ co-catalysts in water splitting ${ }^{[4]}$. For example, $\mathrm{Li}$ et al reported optimal photocatalytic hydrogen production over PtO ${ }^{[5]}$, whereas Xing and co-workers propose electron-deficient (atomically-dispersed) $\mathrm{P}^{\delta+}$ species are superior to metal clusters [6]. In contrast, our preliminary studies on photodeposited $\mathrm{Pt} / \mathrm{TiO}_{2}$ indicate an important role for metallic platinum [7]. This confusion stems in part from the diverse literature syntheses employed to introduce platinum nanoparticles, and attendant variations in $\mathrm{Pt}$ concentration (loading), size, oxidation state and morphology. To date, the impact of different synthetic approaches on the physicochemical properties of $\mathrm{Pt}$ nanoparticle co-catalysts incorporated into titania photocatalysts (the most popular materials for diverse photocatalytic transformations despite their poor spectral response and quantum efficiencies) has not been systematically studied. Hence there is a dearth of efforts to develop simple structural predictors of photocatalytic performance. Recently, an in-situ polyol method proved advantageous in creating such hybrid photocatalysts ${ }^{[8]}$, but remained unsuitable for generating particle sizes $<2.5 \mathrm{~nm}$ from the most common, and low cost, $\mathrm{H}_{2} \mathrm{PtCl}_{6}$ precursor which yielded 6-7 nm diameter particles. Photodeposition (PD) is another method to load metal co-catalysts on a semiconductor photocatalyst. We recently employed PD to produce highly dispersed metallic Pt nanoparticles over titania through varying the methanol concentration during photoirradiation; photocatalytic hydrogen production from water was related to the surface density of Pt metal. However, in the absence of methanol, PD produced predominantly electron-deficient platinum which was unstable with respect to sintering during subsequent photocatalytic hydrogen production. Wetness impregnation is the most general method to load metal nanoparticles over oxide supports [4a-c], but offers poor control over the resulting particle morphology.

Anatase is known to be inactive for splitting pure water (i.e. in the absence of a hole scavenger) into hydrogen and oxygen in the nominal 2:1 stoichiometry ${ }^{[9]}$, hence here we compare the impact of the preceding three routes on the physicochemical properties of Pt co-catalysts on photocatalytic water splitting over anatase in the presence of a sacrificial hole acceptor. $\mathrm{A} \mathrm{pH}$ controlled in-situ polyol synthesis employing a $\mathrm{H}_{2} \mathrm{PtCl}_{6}$ precursor efforts proved an effective route to prepare uniform, highly dispersed Pt metal nanoparticles over titania. Highly dispersed, but electron deficient, Pt nanoparticles were accessible over anatase through tuning wet impregnation. Metallic $\mathrm{Pt}$ is shown to be the active co-catalyst for $\mathrm{H}_{2}$ evolution from water splitting over anatase. 


\section{Results and Discussion}

The physicochemical properties of the four families of $1 \mathrm{wt} \%$ $\mathrm{Pt} / \mathrm{TiO}_{2}$ catalysts were first characterized by a range of bulk and surface sensitive analytical techniques. Figure 1 compares powder XRD patterns of these materials, which all exhibited reflections characteristic of anatase crystallites (JCPDS 21-1272) whose relative intensities and line shapes were essentially identical, indicating a common morphology and volume averaged particle diameter of $\sim 14 \mathrm{~nm}$ (calculated from the Scherrer equation as shown in Table 1), presumably as a consequence of their similar thermal processing history. In contrast, the different synthetic methods resulted in significant variations in the intensity of fcc platinum metal reflections (JCPDS65-2868), with the principal $39.8^{\circ}$ reflection only observed for PD.
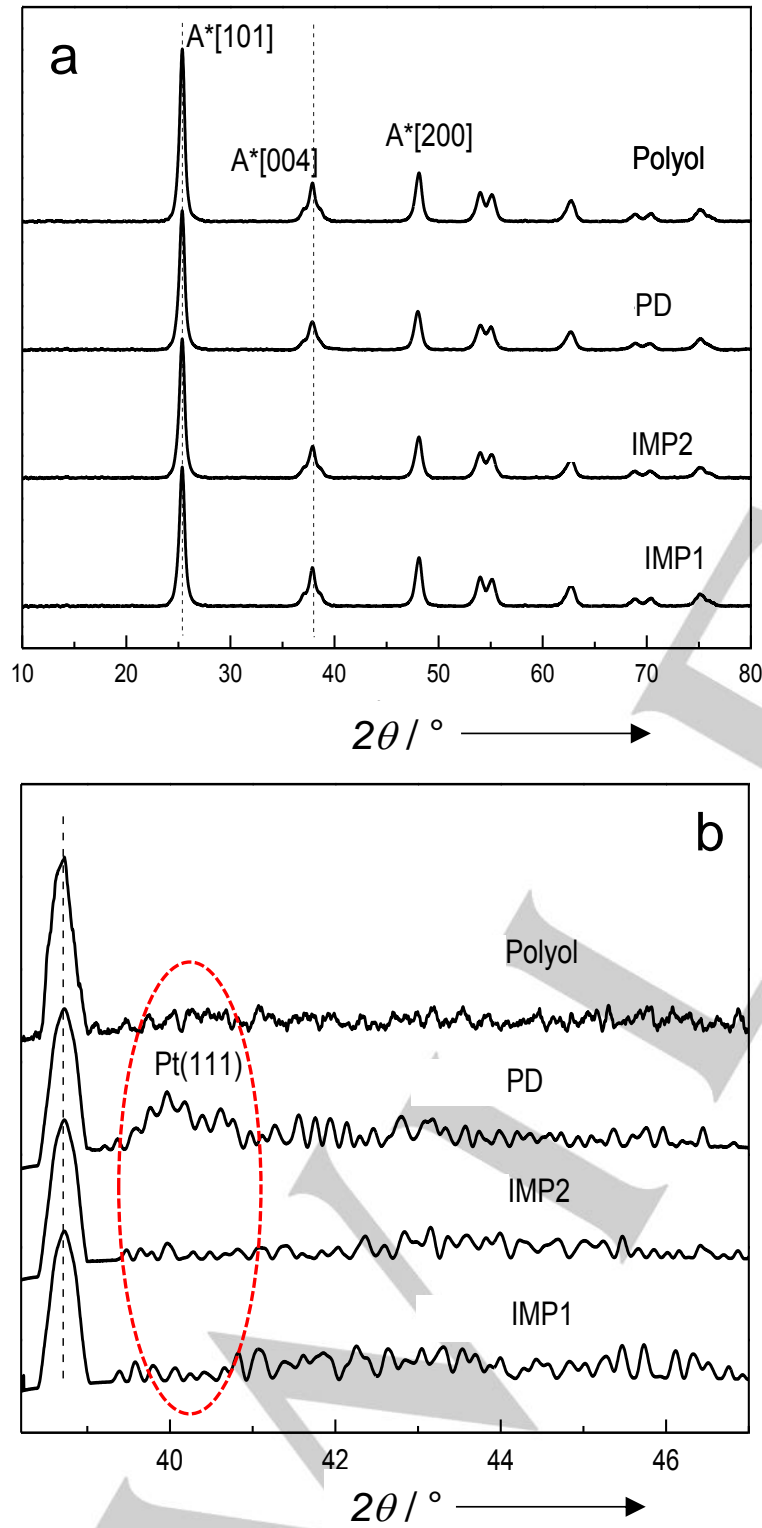

Figure 1. (a-b) Powder XRD pattern of $1 w t \% ~ P t / T i O_{2}$ catalysts as a function of synthetic route, highlighting fcc platinum reflection. $A^{*}=$ anatase phase titania.
Figure 2 compares the DRUV spectra of the as-prepared $\mathrm{Pt} / \mathrm{TiO}_{2}$ samples. All materials exhibited similar optical properties, with strong absorption edges at about $390 \mathrm{~nm}$ due to the band gap absorption of pure anatase $\mathrm{TiO}_{2}$. Nitrogen porosimetry of the $1 \mathrm{wt} \% \mathrm{Pt} / \mathrm{TiO}_{2}$ samples confirmed they possessed similar textural properties, with the four synthetic routes affording a common surface area of approximately $110 \mathrm{~m}^{2} \cdot \mathrm{g}^{-1}$ (Table 1). Elemental analysis also confirmed that the actual and nominal loadings of all four $1 \mathrm{wt} \% \mathrm{Pt} / \mathrm{TiO}_{2}$ were essentially identical; the absence of metallic Pt diffraction features for the wet impregnation and in-situ polyol syntheses is thus indicative of the presence of highly dispersed, or oxidic, Pt species over the anatase support. It is important to note that any differences between the catalytic performances of these materials (described subsequently) cannot therefore be attributed to variations in either titania phase/morphology, or platinum loading.

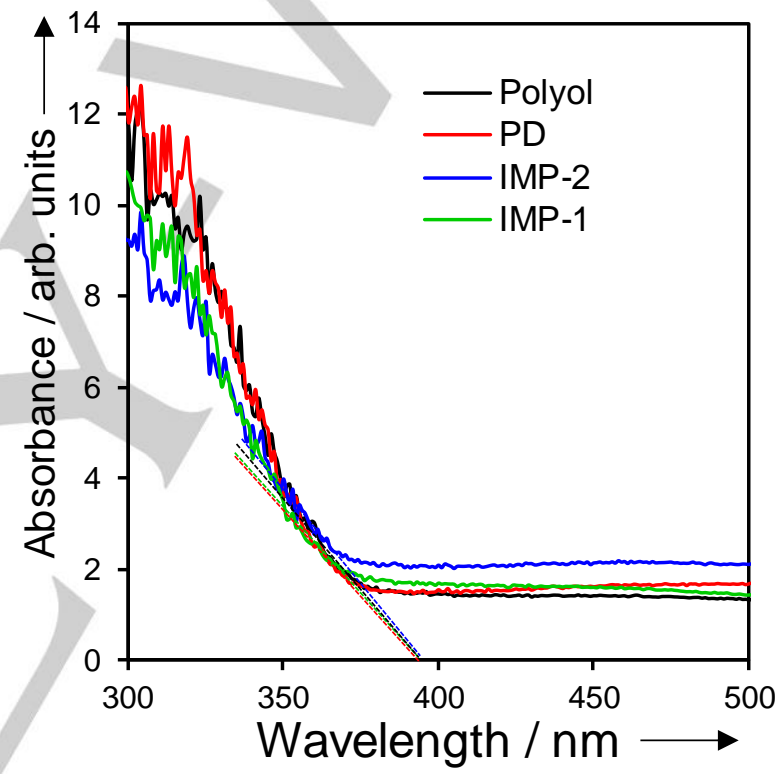

Figure 2. DRUV spectra of $1 \mathrm{wt} \% \mathrm{Pt} / \mathrm{TiO}_{2}$ catalysts as a function of synthetic route.

Table 1. Structural properties of $1 \mathrm{wt} \% \mathrm{Pt} / \mathrm{TiO}_{2}$ catalysts

\begin{tabular}{|c|c|c|c|}
\hline Sample & $\begin{array}{l}\text { Pt } \\
\text { loading } \\
\text { / wt } \%\end{array}$ & $\begin{array}{l}\text { BET surface } \\
\text { area } a^{[b]} \\
/ \mathrm{m}^{2} \cdot \mathrm{g}^{-1}\end{array}$ & $\begin{array}{l}\text { Anatase particle } \\
\text { size } \\
/ \mathrm{nm}\end{array}$ \\
\hline $\mathrm{Pt} / \mathrm{TiO}_{2}-\mathrm{Polyol}$ & 1.09 & 107 & 13.4 \\
\hline $\mathrm{Pt} / \mathrm{TiO}_{2}-\mathrm{PD}$ & 1.06 & 106 & 13.2 \\
\hline $\mathrm{Pt} / \mathrm{TiO}{ }_{2}-\mathrm{IMP}-2$ & 1.06 & 108 & 14.0 \\
\hline $\mathrm{Pt} / \mathrm{TiO}{ }_{2}-\mathrm{IMP}-1$ & 1.08 & 109 & 13.9 \\
\hline
\end{tabular}

${ }^{[\mathrm{a}]}$ ICP-AES; ${ }^{[\mathrm{b}]} \mathrm{N} 2$ porosimetry; ${ }^{[\mathrm{c}]} \mathrm{XRD}$.

Platinum particle morphologies for the $1 \mathrm{wt} \% \quad \mathrm{Pt} / \mathrm{TiO}_{2}$ materials were investigated by HAADF-STEM (Figure 3). Both wet impregnation and the in-situ polyol syntheses resulted in 

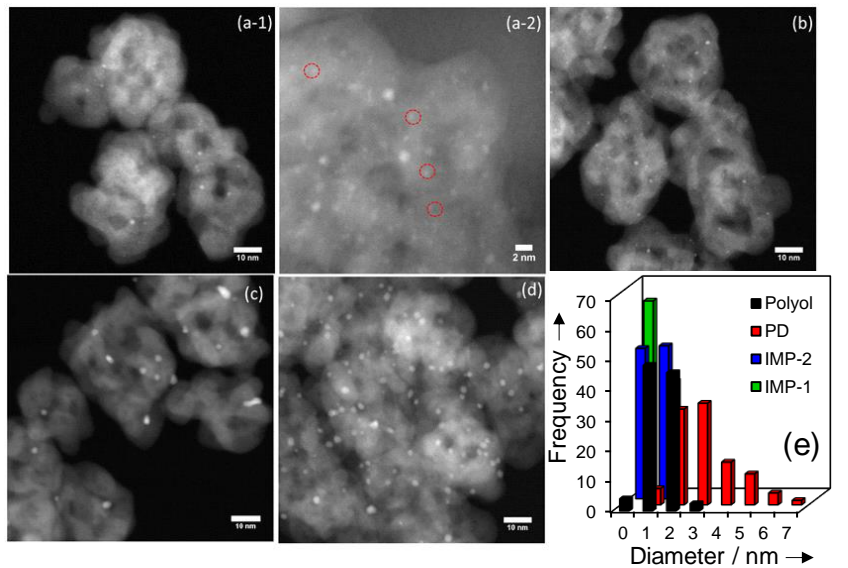

Figure 3. HAADF-STEM images of $1 \mathrm{wt} \% \mathrm{Pt} / \mathrm{TiO}_{2}$ catalysts as a function of synthetic route: (a-1 and a-2) IMP-1; (b) IMP-2; (c) PD; (d) in-situ polyol; and (e) corresponding Pt particle size distributions.

small Pt nanoparticles below $2 \mathrm{~nm}$, of which the latter were almost monodispersed at $2 \pm 0.25 \mathrm{~nm}$ (Figure $3 \mathrm{~d}$-e). Pt nanocrystals produced in the present in-situ polyol method (performed at $\mathrm{pH}$ 9) differ from those previously reported without $\mathrm{pH}$ regulation ${ }^{[8 \mathrm{a}]}$ in which the same $\mathrm{H}_{2} \mathrm{PtCl}_{6}$ precursor produced far larger $7 \mathrm{~nm}$ particles. This suggests that $\mathrm{pH}$ plays strongly influences the reduction kinetics and hence size control; indeed basic conditions are known to accelerate ethylene glycol dehydration to acetaldehyde [10], the latter being a potent reductant of metal salts which likely promotes metal nanoparticle nucleation versus growth. In contrast, PD resulted in a broad distribution of $\mathrm{Pt}$ nanoparticle sizes, spanning $1.5-7.5 \mathrm{~nm}$, and irregular shapes (Figure 3c). Lattice fringes of the anatase and metallic $\mathrm{Pt}$ components of the $1 \mathrm{wt} \% \mathrm{Pt} / \mathrm{TiO}_{2}$ samples were also visualised by bright-field TEM (Figure 4). Figure 4 also evidences a close interaction of $\mathrm{Pt}$ with the titania surface, notably for $1 \mathrm{wt} \% \mathrm{Pt} / \mathrm{TiO}_{2-}$ IMP1 wherein the oxide support appears to have partially encapsulated a platinum nanoparticle characteristic of a classical strong metal-support interaction. Wet impregnation of precalcined anatase $\left(1 \mathrm{wt} \% \mathrm{Pt} / \mathrm{TiO}_{2}-\mathrm{IMP} 2\right)$ resulted in a slightly broader and larger mean particle size relative to direct impregnation of the as-prepared anatase ( $\left.1 \mathrm{wt} \% \mathrm{Pt} / \mathrm{TiO}_{2}-\mathrm{IMP} 2\right)$ which may reflect a smaller number of vacancies in the former which act as surface nucleation sites for Pt species.

Surface compositions and platinum oxidation states were determined by XPS (detailed fitted parameters provided in Table S1). Figure 5 shows the resulting Pt $4 \mathrm{f} X \mathrm{P}$ spectra of the $1 \mathrm{wt} \%$ $\mathrm{Pt} / \mathrm{TiO}_{2}$ samples which exhibit the expected spin-orbit split doublets separated by $\sim 3.3 \mathrm{eV}$. All spectra could be fitted with either a $4 \mathrm{f}_{7 / 2}$ metallic component at $70 \mathrm{eV}$ binding energy, a $\mathrm{Pt}^{4+}$ component at $73.4 \mathrm{eV}$ attributable to $\mathrm{PtO}_{2}$, or an intermediate state $71.2 \mathrm{eV}$ which has been previously assigned to Pt-O-Ti species ${ }^{[11]}$. Only metallic $\mathrm{Pt}$ was observed for the $1 \mathrm{wt} \% \mathrm{Pt} / \mathrm{TiO}_{2-}$ Polyol (Figure 6), which also exhibited the highest total surface Pt content ( 0.29 atom\%) and hence dispersion of platinum over the anatase support. This finding is consistent with XRD and TEM, and confirms that the modified in-situ polyol synthesis was most
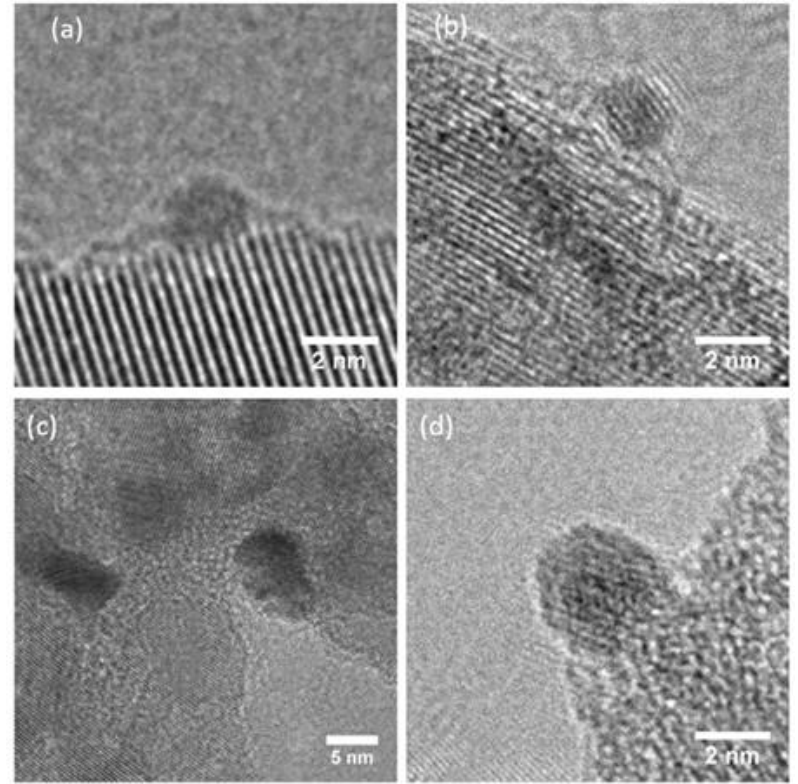

Figure 4. Representative bright-field HRTEM images of $1 \mathrm{wt} \% \mathrm{Pt} / \mathrm{TiO} 2$ as a function of synthetic route: (a) IMP-1; (b) IMP-2; (c) PD; (d) in-situ polyol

effective in creating small (almost entirely) metallic $\mathrm{Pt}$ nanoparticles. PD also favoured metallic nanoparticles, with only $\sim 24 \%$ of surface platinum in oxidised form, but with a significantly lower surface $\mathrm{Pt}$ content $(0.17$ atom\%) consistent with larger particles. In contrast, both wet impregnation syntheses favoured heavily oxidised platinum (87-96 \% $\left.\mathrm{PtO}_{2} / \mathrm{Pt}-\mathrm{O}-\mathrm{Ti}\right)$, almost entirely due to the formation of interfacial $\mathrm{Pt}-\mathrm{O}-\mathrm{Ti}$ species arising from the high temperature calcination steps and subsequent incomplete reduction (the latter is known to promote a strong $\mathrm{Ti}-\mathrm{O}-\mathrm{Pt}$ interaction ${ }^{[12]}$. Wet impregnation also yielded the lowest total surface $\mathrm{Pt}: \mathrm{Ti}$ atomic ratios, indicating the poorest $\mathrm{Pt}$ dispersion.

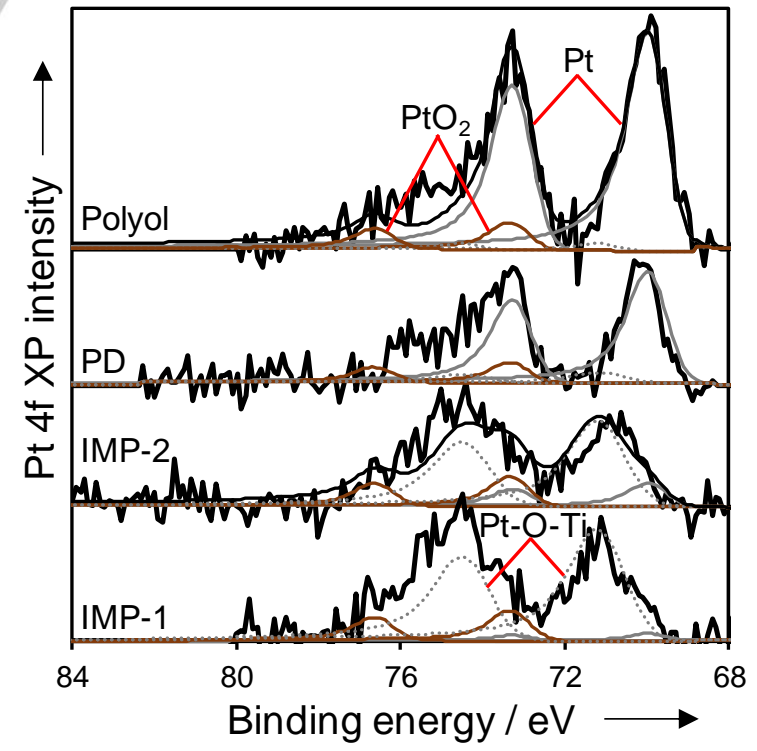

Figure 5. Fitted $\mathrm{Pt} 4 \mathrm{fP}$ spectra of $1 \mathrm{wt} \% \mathrm{Pt} / \mathrm{TiO}_{2}$ catalysts as a function of synthetic route. 


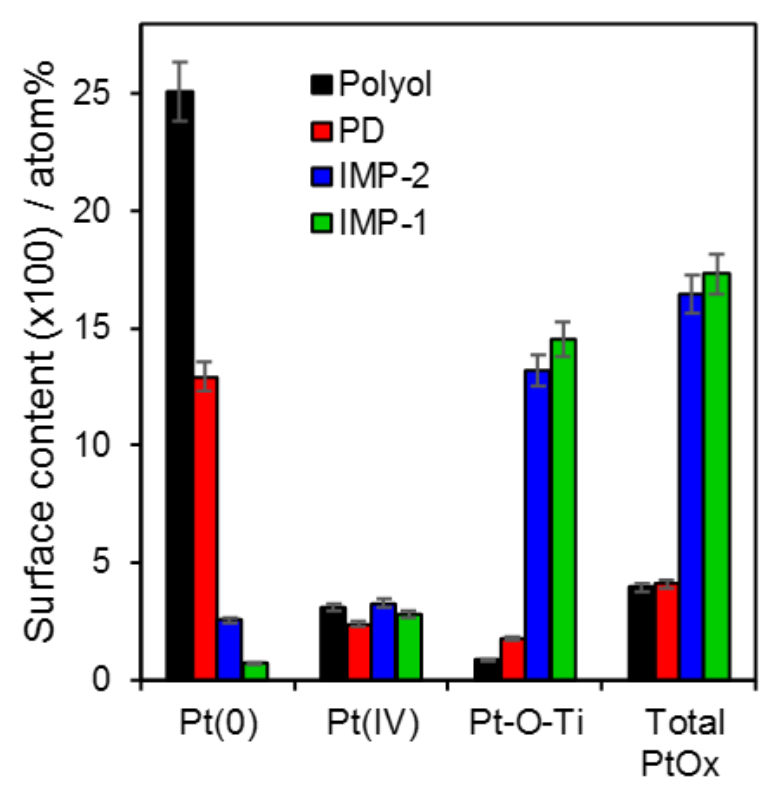

Figure 6. Evolution of surface platinum species of $1 \mathrm{wt} \% \mathrm{Pt} / \mathrm{TiO}_{2}$ catalysts as a function of synthetic route.

The mean oxidation state of platinum within the $1 \mathrm{wt} \%$ $\mathrm{Pt} / \mathrm{TiO}_{2}$ samples was also explored by XAS. Pt $\mathrm{L}_{\| 11}$-edge XANES in Figure 7a confirm that both the in-situ polyol and PD routes yielded spectra almost identical to bulk Pt metal, whereas both wet impregnation routes resulted in spectra with features characteristic of $\mathrm{PtO}_{2}$, in excellent agreement with XPS. Corresponding radial distribution functions (Figure $7 b$ ) reveal a strong Pt-Pt nearest neighbor scattering around $2.78 \AA$ for both in-situ polyol and PD samples, confirming the formation of metallic nanoparticles [13]; the weaker intensity of this feature for the in-situ polyol sample suggests that it comprises smaller particles, consistent with XRD, TEM and XPS. Preparation by wet impregnation resulted in a strong $\mathrm{Pt}-\mathrm{O}$ scatterer around $1.95 \AA$ and weak Pt-Pt feature, consistent with partially oxidized Pt metal nanoparticles arising from the calcination step and/or strong interaction with the anatase support.

Figure 8 presents the corresponding photocatalytic activity of the $1 \mathrm{wt} \% \mathrm{Pt} / \mathrm{TiO}_{2}$ materials, which exhibit a strong sensitivity on the preparative route. $\mathrm{H}_{2}$ evolution was linear with reaction time, evidencing negligible deactivation, in all cases. Activity decreased in the order $\mathrm{Pt} / \mathrm{TiO}_{2}-\mathrm{Polyol}>\mathrm{Pt} / \mathrm{TiO}_{2}-\mathrm{PD}>\mathrm{Pt} / \mathrm{TiO}_{2}-$ IMP-2 > $\mathrm{Pt} / \mathrm{TiO}_{2}-\mathrm{IMP}_{-}$, precisely mirroring the proportion of surface Pt metal from XPS and evidencing a direct correlation between the platinum oxidation state and degree of titania promotion. The $1 \mathrm{wt} \% \mathrm{Pt} / \mathrm{TiO}_{2}-\mathrm{Polyol}$ catalysts evolved $82 \%$ and $51 \%$ more hydrogen than equivalent $\mathrm{Pt} / \mathrm{TiO}_{2}-\mathrm{IMP} 1$ and $\mathrm{Pt} / \mathrm{TiO}_{2^{-}}$ IMP2 catalysts. Note that identical trends were observed for 0.5 and $2 \mathrm{wt} \% \mathrm{Pt} / \mathrm{TiO}_{2}$ catalysts (Figure S1), highlighting the general superiority of the in-situ polyol synthesis which still offered highly dispersed $(2 \mathrm{~nm}$ ) particles for the $2 \mathrm{wt} \%$ loading (Figure S2). The importance of metallic $\mathrm{Pt}$ as a co-catalyst most likely arises from either improved charge separation (e.g. acting as electron trap centers) or providing surface sites for hydrogen recombination [3e].
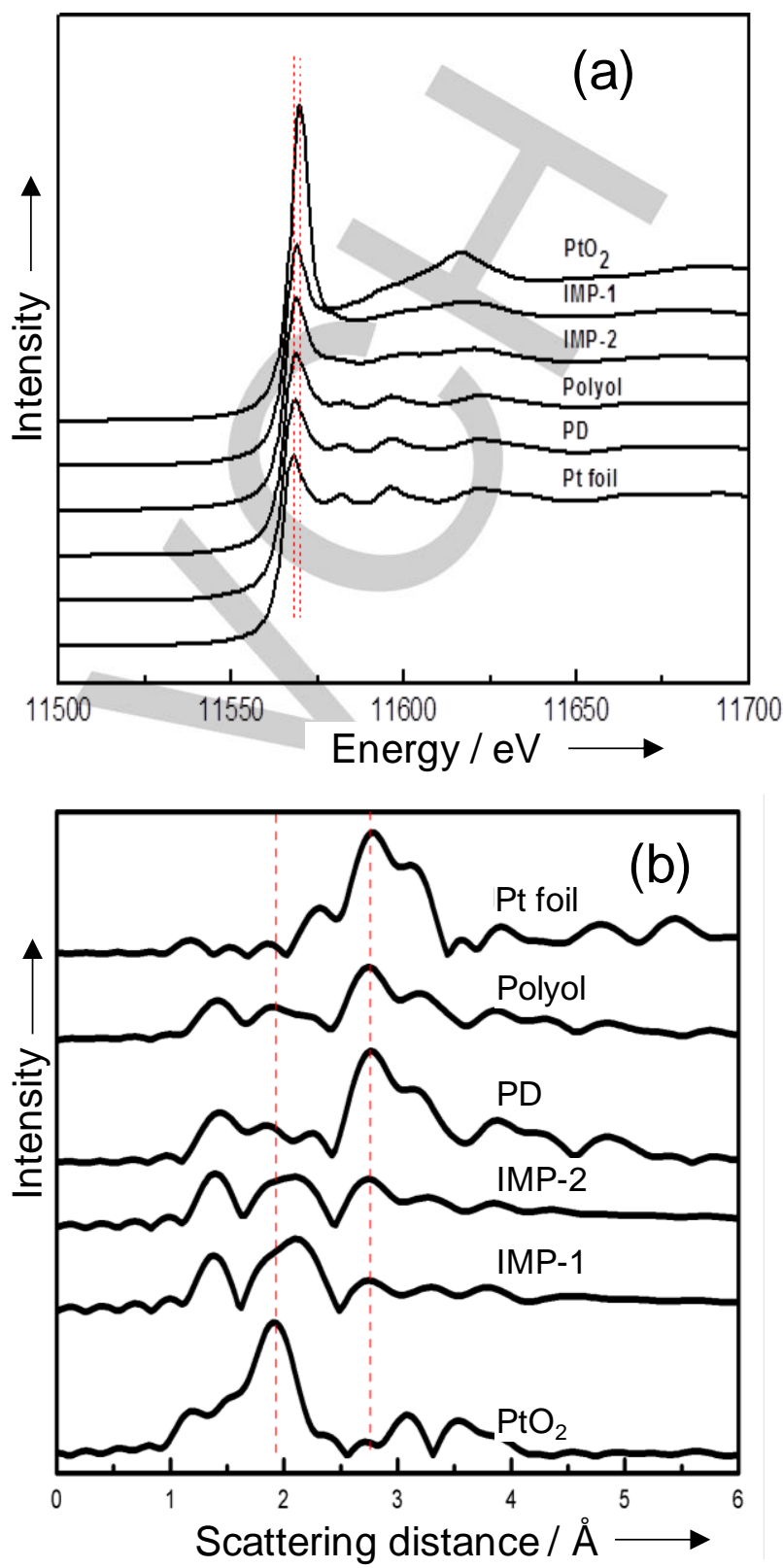

Figure 7. Pt LiII-edge (a) normalized fluorescence XANES spectra and (b) corresponding radial distribution functions of $1 \mathrm{wt} \% \mathrm{Pt} / \mathrm{TiO}_{2}$ catalysts as function of synthetic route. Pt foil and oxide references shown for comparison.

The preceding observations are consistent with our previous study using PD to introduce Pt co-catalyst into P25 titania, ${ }^{[7]}$ where, in the absence of methanol during the catalyst synthesis, a high density of small, oxidic Pt nanoparticles were formed which exhibited poor subsequent activity for aqueous photocatalytic hydrogen production. Such oxidic nanoparticles were also unstable with respect to in-situ reduction and sintering to form large and inhomogeneous Pt metal nanoparticles. Methanol introduction during the PD step in the present work 

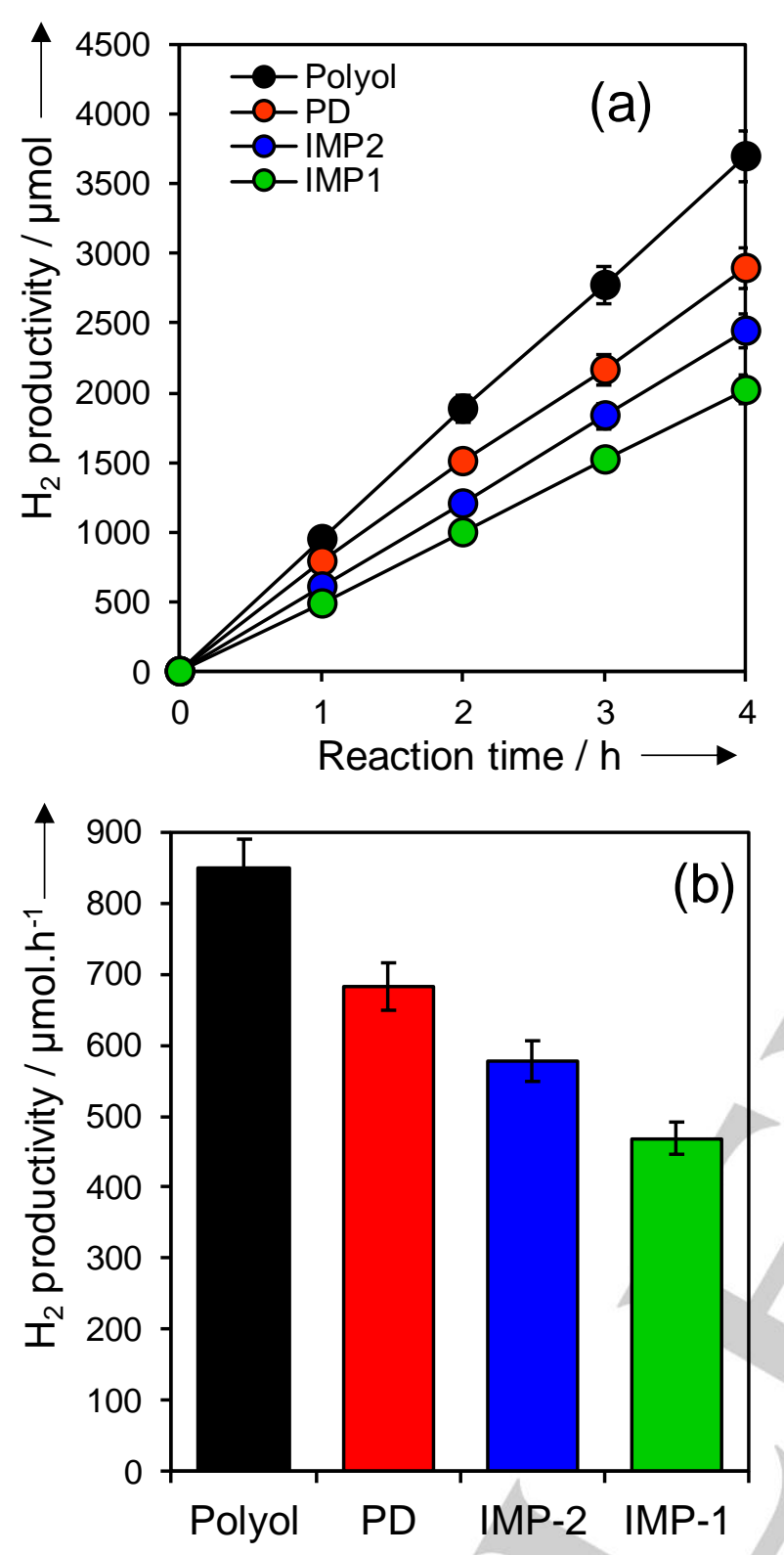

Figure 8. (a) Photocatalytic hydrogen reaction profile and (b) $\mathrm{H}_{2}$ productivity of $1 \mathrm{wt} \% \mathrm{Pt} / \mathrm{TiO}_{2}$ catalysts as a function of synthetic route. Reaction conditions: 50 $\mathrm{mg}$ catalyst, $80 \mathrm{ml}$ water and $20 \mathrm{ml}$ methanol.

circumvents these issues. We note that despite the high temperature reduction $\left(400^{\circ} \mathrm{C}\right)$ step employed therein, neither of the two wet impregnation routes in this work were as effective as liquid phase chemical reductions in producing metallic $\mathrm{Pt}$, presumably due to SMSI phenomena which stabilize (or partially encapsulate) oxidic platinum. The principal factor influencing the performance of nanoparticulate $\mathrm{Pt}$ co-catalysts in promoting photocatalytic $\mathrm{H}_{2}$ production over anatase is the interfacial concentration of metallic Pt (Figure 9 a). Note that pure anatase produced only $55 \mu \mathrm{mol} / \mathrm{h}$ of hydrogen, hence the significant $\mathrm{y}$-axis intercept (of $\sim 300 \mu \mathrm{mol} / \mathrm{h}$ of hydrogen in terms of surface $\mathrm{Pt} \mathrm{t}^{0}: \mathrm{Ti}$ atomic ratio, Fig. S3) indicates there must be a minimum

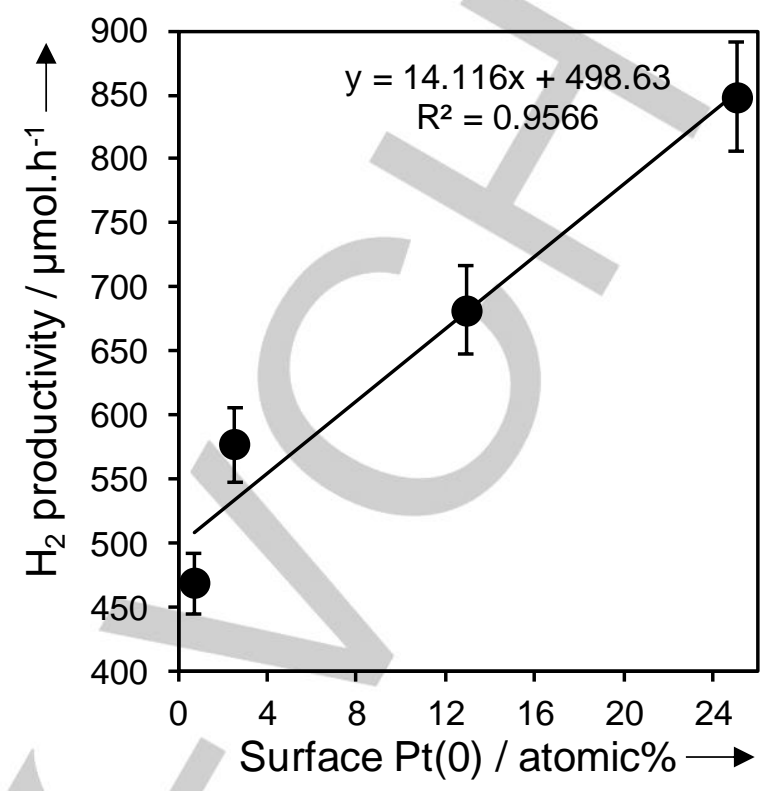

Figure 9. Linear relationship between surface $\mathrm{Pt}$ metal concentration and photocatalytic $\mathrm{H}_{2}$ productivity over $1 \mathrm{wt} \% \mathrm{Pt} / \mathrm{TiO}_{2}$. Reaction conditions: $50 \mathrm{mg}$ catalyst, $80 \mathrm{ml}$ water and $20 \mathrm{ml}$ methanol.

ensemble of $\mathrm{Pt}$ atoms below which water splitting cannot be sustained, possibly due to both geometric and electronic factors.

\section{Conclusions}

The impact of wet chemical synthetic route on the physicochemical properties of platinum co-catalysts introduced by post-modification of a hydrothermally prepared anatase titania was investigated by bulk and surface analysis. Wet impregnation of as-prepared or pre-calcined anatase by chloroplatinic acid favored the formation of highly oxidized platinum nanoparticles, likely due to a strong-metal support interaction that stabilized interfacial Pt-O-Ti species. In contrast, photodeposition and an insitu polyol synthesis performed under basic conditions both yield metallic Pt, with the in-situ polyol method particularly effective at forming highly dispersed $(<2 \mathrm{~nm})$ nanoparticles over anatase. Cocatalyst introduction by any route had negligible impact on the phase or morphology of the anatase support. Subsequent photocatalytic water splitting under UV-Vis irradiation revealed a direct correlation between the surface Pt metal concentration and evolved $\mathrm{H}_{2}$ productivity, identifying metallic platinum as the active co-catalyst. The modified in-situ polyol route to $\mathrm{Pt}$ co-catalyst incorporation offers significant rate enhancements $(25-80 \%)$ relative to other conventional routes, and unlocks strategies to optimize other photocatalytic reactions such as $\mathrm{CO}_{2}$ reduction which employ platinum co-catalysts. 


\section{Experimental Section}

\section{Anatase synthesis}

Anatase titania was prepared by a hydrothermal route as follows. $130 \mathrm{ml}$ titanium(IV) sulfate (Sinoreagent) aqueous solution $(0.625 \mathrm{M})$ was placed in a $250 \mathrm{~mL}$ Teflon-lined stainless steel autoclave and heated to $130^{\circ} \mathrm{C}$ for $8 \mathrm{~h}$. After cooling the resulting suspension was filtered, washed with water and (ethanol) until the filtrate was $\mathrm{pH} 7$, and dried at $80^{\circ} \mathrm{C}$ overnight to yield a white powder. $\mathrm{Pt} / \mathrm{TiO}_{2}$ was prepared by four different procedures using the preceding titania with identical $0.5,1$ and 2 wt\% Pt loadings, however a detailed physicochemical characterization was only undertaken on the $1 \mathrm{wt} \%$ materials. Similar thermal processing treatments were employed for each synthetic route to minimize perturbation of the anatase support.

\section{Wet impregnation}

Two series of $\mathrm{Pt} / \mathrm{TiO}_{2}$ catalysts were prepared by wet impregnation from $\mathrm{H}_{2} \mathrm{PtCl}_{6}$. In the first, $1 \mathrm{~g} \mathrm{TiO}$ was mixed with the desired concentration of aqueous chloroplatinic acid $\left(\mathrm{H}_{2} \mathrm{PtCl}_{6}\right.$, Sinoreagent), subject to $30 \mathrm{~min}$ ultrasonication with stirring, and then evaporated to dryness under stirring at $80^{\circ} \mathrm{C}$. The resulting powders were subsequently dried at $110{ }^{\circ} \mathrm{C}$ for 12 $\mathrm{h}$ and then calcined at $400{ }^{\circ} \mathrm{C}$ (ramp rate $\left.2.5^{\circ} \mathrm{C} / \mathrm{min}\right)$ in air for $8 \mathrm{~h}$, and finally reduced in flowing hydrogen at $400{ }^{\circ} \mathrm{C}$ (ramp rate $2.5^{\circ} \mathrm{C} / \mathrm{min}$ ) for 1 h. These are denoted $\mathrm{Pt} / \mathrm{TiO}_{2}-\mathrm{IMP}-1$. The second series were prepared similarly, but employing $\mathrm{TiO}_{2}$ pre-calcined at $400{ }^{\circ} \mathrm{C}$ (ramp rate $2.5^{\circ} \mathrm{C} / \mathrm{min}$ ) for $4 \mathrm{~h}$ prior to impregnation with $\mathrm{H}_{2} \mathrm{PtCl}_{6}$, and with a decreased subsequent calcination time of only $4 \mathrm{~h}$ to ensure the titania experienced a total calcination time of $8 \mathrm{~h}$ akin to the first series. The second series is denoted $\mathrm{Pt} / \mathrm{TiO}$-IMP-2.

\section{Photodeposition}

PD was conducted within a Pyrex topped reaction cell. The $\mathrm{TiO}_{2}$ was precalcined in air at $400{ }^{\circ} \mathrm{C}$ for $8 \mathrm{~h}$ (ramp rate $2.5^{\circ} \mathrm{C} / \mathrm{min}$ ) and reduced in hydrogen at $400{ }^{\circ} \mathrm{C}$ for 1 hour (heating rate $2.5^{\circ} \mathrm{C} / \mathrm{min}$ ). $1 \mathrm{~g}$ of the precalcined $\mathrm{TiO}_{2}$ was subsequently suspended in $80 \mathrm{ml}$ water and $20 \mathrm{ml}$ methanol at $25{ }^{\circ} \mathrm{C}$ to which an appropriate amount of $\mathrm{H}_{2} \mathrm{PtCl}_{6}$ was added, subject to $30 \mathrm{~min}$ ultrasonication with stirring, and the reaction vessel subsequently evacuated prior to irradiation with a $300 \mathrm{~W}$ Xe lamp for $1 \mathrm{~h}$. The photodeposited powders were filtered and washed with water prior to in vacuo drying at $80^{\circ} \mathrm{C}$ for $12 \mathrm{~h}$. These catalysts are denoted $\mathrm{Pt} / \mathrm{TiO}_{2}-\mathrm{PD}$.

\section{In-situ polyol}

An in-situ polyol method was adapted from our recent work [8a], in which the $\mathrm{pH}$ was changed to 9.0 by $2 \mathrm{M} \mathrm{NaOH}$ solution addition. In a typical procedure, the appropriate quantity of $\mathrm{H}_{2} \mathrm{PtCl}_{6}, 0.1735 \mathrm{~g}$ of tetramethylammonium bromide (Aldrich), $0.1665 \mathrm{~g}$ of polyvinylpyrrolidone (Aldrich, 29,000 MW) were added to $1 \mathrm{~g}$ of $\mathrm{TiO}_{2}$ and $30 \mathrm{~mL}$ of ethylene glycol in a $100 \mathrm{~mL}$ round-bottomed flask at $60^{\circ} \mathrm{C}$ and subject to $30 \mathrm{~min}$ ultrasonication with stirring. The mixture was then purged with $\mathrm{Ar}$ and rapidly heated to $180^{\circ} \mathrm{C}$ in an oil bath and held at temperature for $25 \mathrm{~min}$ under magnetic stirring to yield a dark brown solution. After cooling to room temperature, the solution was centrifuged at $3000 \mathrm{rpm}$ for $5 \mathrm{~min}$, and a dark blue powder collected by discarding the colorless supernatant. The powder was then washed three times by precipitation/dissolution (redispersed in $10 \mathrm{~mL}$ of ethanol and then precipitated by adding $40 \mathrm{~mL}$ of hexane). $0.5 \mathrm{~g}$ of the resulting powders was dispersed in $100 \mathrm{ml} \mathrm{H}_{2} \mathrm{O}$ and irradiated with a $300 \mathrm{~W}$ Xe lamp for $6 \mathrm{~h}$ under bubbling air [8b]. This treatment effectively removes organic ligands from the surface of $\mathrm{Pt} / \mathrm{TiO}_{2}$ without perturbing the physicochemical properties of the underlying as-synthesised catalyst ${ }^{[8 b]}$. The final powders were filtered and washed with water prior to in vacuo drying at $80^{\circ} \mathrm{C}$ for $12 \mathrm{~h}$.

\section{Characterization}

Elemental analysis of as-prepared $\mathrm{Pt} / \mathrm{TiO}_{2}$ samples were examined by inductively coupled plasma atomic emission spectroscopy (ICP-AES iCAP 6000 Radial, Thermo). Crystallinity was measured by powder X-ray diffraction (XRD) on a Bruker D8 Advance Da Vinci diffractometer. Optical properties were probed by diffuse reflectance UV-Vis spectroscopy (DRUVS) using a Shimadzu UV-2450 spectrophotometer. X-ray photoelectron spectra were acquired on a Kratos HSi spectrometer equipped with a charge neutralizer and monochromated $\mathrm{Al} \mathrm{K}_{\alpha}$ excitation source $(1486.7 \mathrm{eV})$. Binding energies were referenced to adventitious carbon at $284.6 \mathrm{eV}$. Spectral fitting was performed using a common asymmetric peak shape. Errors were estimated by varying the Shirley background-subtraction procedure across reasonable limits and recalculating the components fits. Fluorescence Pt LIII-edge X-ray absorption spectra (XAS) were acquired with a Lytle detector on the BL14W1 beamline of the Shanghai Synchrotron Radiation Facility (SSRF), Shanghai Institute of Applied Physics (SINAP), China, operated at $3.5 \mathrm{GeV}$ with injection currents of 140-210 mA. Brunauer-Emmett-Teller (BET) surface areas were measured using a TriStar II 3020 Micromeritics porosimeter via nitrogen physisorption at $77 \mathrm{~K}$. Transmission electron microscopy (TEM), high angle annular dark field scanning transmission electron microscopy (HAADF)-STEM and elemental mapping was performed on a FEI Talos F200X microscope operated at $200 \mathrm{kV}$. Particle size distributions were determined from analysis of 200 particles for all samples.

\section{Catalytic testing}

Photocatalytic water splitting was conducted in the Pyrex topped reaction cell employing $50 \mathrm{mg}$ of $\mathrm{Pt} / \mathrm{TiO}_{2}$ catalyst dispersed in $80 \mathrm{ml}$ water and 20 $\mathrm{ml}$ methanol at $25^{\circ} \mathrm{C}$, equilibrated in the dark for $30 \mathrm{~min}$. The reaction cell was subsequently evacuated and irradiated by a $300 \mathrm{~W}$ Xe lamp to provide an approximate flux inside the reaction vessel of $130 \mathrm{~mW} / \mathrm{cm}^{-2}$. Evolved gases in the reactor headspace were analyzed by gas chromatography (GC-9200 equipped with TCD, employing a $6 \mathrm{~m} \times 2 \mathrm{~mm} \times 250 \mu \mathrm{m}$ MS-5A column). Evolved oxygen was not detected in any experiment, even using pure water in the absence of methanol as a hole scavenger, consistent with literature for $\mathrm{PtTiO}_{2}$ (anatase) ${ }^{[9]}$. Note that the parent anatase evolved $\sim 55 \mu \mathrm{mol} / \mathrm{h}$ of hydrogen in the absence of platinum.

\section{Acknowledgements}

We thank the National Key R\&D Program of China(2016YFC0207103), Shanghai Natural Science Foundation (14ZR1421900), National Science Foundation of China (50906050) and EPSRC (EP/K021796/1 and EP/K029525/2) for financial support.

Keywords: Platinum $\bullet \mathrm{TiO}_{2} \cdot$ co-catalyst $\bullet$ water splitting $\bullet$ XPS A. Fujishima, Nature 1972, 238, 37-38.

[2] a) J. Cai, M. Wu, Y. Wang, H. Zhang, M. Meng, Y. Tian, X. Li, J. Zhang, L. Zheng, J. Gong, Chem 2017, 2, 877892; b) J. Cai, Y. Wang, Y. Zhu, M. Wu, H. Zhang, X. Li, Z. Jiang, M. Meng, ACS applied materials \& interfaces 
2015, 7, 24987-24992; c) Y. Wang, J. Cai, M. Wu, H. Zhang, M. Meng, Y. Tian, T. Ding, J. Gong, Z. Jiang, X. $\mathrm{Li}$, ACS applied materials \& interfaces 2016, 8, 2300623014; d) M. Ni, M. K. Leung, D. Y. Leung, K. Sumathy, Renewable and Sustainable Energy Reviews 2007, 11, 401-425.

[3] a) X. Chen, S. Shen, L. Guo, S. S. Mao, Chem. Rev. 2010, 110, 6503-6570; b) K. Maeda, K. Domen, J. Phys. Chem. Lett. 2010, 1, 2655-2661; c) R. Abe, J. Photochem. Photobiol. C 2010, 11, 179-209; d) J. Yang, D. Wang, H. Han, C. Li, Acc. Chem. Res. 2013, 46, 1900-1909; e) A. Kudo, Catal. Surv. Asia 2003, 7, 3138; f) J. S. Lee, Catal. Surv. Asia 2005, 9, 217-227; g) J.-M. Herrmann, Catal. Today 1999, 53, 115-129.

[4] a) S. K. Parayil, H. S. Kibombo, C.-M. Wu, R. Peng, T. Kindle, S. Mishra, S. P. Ahrenkiel, J. Baltrusaitis, N. M. Dimitrijevic, T. Rajh, J. Phys. Chem. C 2013, 117, 16850-16862; b) C.-H. Lin, J.-H. Chao, C.-H. Liu, J.-C. Chang, F.-C. Wang, Langmuir 2008, 24, 9907-9915; c) R. Navarro, J. Arenales, F. Vaquero, I. González, J. Fierro, Catal. Today 2013, 210, 33-38; d) X. Jiang, X. Fu, L. Zhang, S. Meng, S. Chen, J. Mater. Chem. 2015, 3, 2271-2282.

[5] Y. H. Li, J. Xing, Z. J. Chen, Z. Li, F. Tian, L. R. Zheng, H. F. Wang, P. Hu, H. J. Zhao, H. G. Yang, Nat. Commun. 2013, 4, 2500.

[6] J. Xing, J. F. Chen, Y. H. Li, W. T. Yuan, Y. Zhou, L. R. Zheng, H. F. Wang, P. Hu, Y. Wang, H. J. Zhao, Y. Wang, H. G. Yang, Chem. Eur. J. 2014, 20, 2138-2144.

[7] Z. Jiang, Z. Zhang, W. Shangguan, M. A. Isaacs, L. J. Durndell, C. M. A. Parlett, A. F. Lee, Catal. Sci. Tech. 2016, 6, 81-88.

[8] a) Z. Jiang, H. Guo, Z. Jiang, G. Chen, L. Xia, W. Shangguan, X. Wu, Chem. Commun. 2012, 48, 95989600; b) Z. Jiang, W. Shangguan, Catal. Today 2015, 242, 372-380.

[9] R. Li, Y. Weng, X. Zhou, X. Wang, Y. Mi, R. Chong, H. Han, C. Li, Energy Environ. Sci. 2015, 8, 2377-2382.

[10] R. J. Joseyphus, T. Matsumoto, H. Takahashi, D. Kodama, K. Tohji, B. Jeyadevan, Journal of Solid State Chemistry 2007, 180, 3008-3018.

[11] a) L. K. Ono, B. Yuan, H. Heinrich, B. R. Cuenya, J. Phys. Chem. C 2010, 114, 22119-22133; b) F. Pesty, H.-P. Steinrück, T. E. Madey, Surf. Sci. 1995, 339, 8395.

[12] J. Zhang, M. Zhang, Z. Jin, J. Wang, Z. Zhang, Appl. Surf. Sci. 2012, 258, 3991-3999.

[13] A. I. Frenkel, C. W. Hills, R. G. Nuzzo, J. Phys. Chem. B 2001, 105, 12689-12703. 


\section{Entry for the Table of Contents}

\section{FULL PAPER}

Pt metal is the active cocatalyst in photocatalytic $\mathrm{H}_{2}$ production over anatase titania

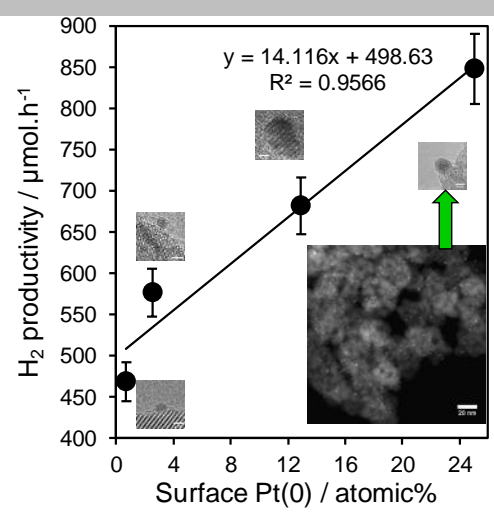

Zhi Jiang, ${ }^{*[a]}$ Mark A. Isaacs, ${ }^{[b]}$ Wenfeng Shangguan, ${ }^{[a]}$ Yifeng Deng, ${ }^{[c]}$ and Adam F. Lee ${ }^{*[b]}$

Page No. - Page No.

Rational design of Pt co-catalysts for photocatalytic hydrogen production over titania 